\title{
DOGUMENTOS
}

\section{EL TESTAMENTO DE JOSÉ MIGUEL RIVERA SARAVIA, ARQUITECTO DEL SIGLO XVIII}

\section{Por Eduardo Báez Macias}

José Miguel Rivera Saravia, arquitecto y maestro de ensamblador y de carpintería, trabajó en la ciudad de México durante la primera mitad del siglo xvir, en las décadas que precedieron al florecimiento de la soberbia arquitectura churrigueresca. En el archivo del Hospital de Jesús, hoy ramo del Archivo General, existen algunas noticias tocantes a su vida y obras, como el testamento otorgado cuando ya sentía que sus días se acababan, y que he seleccionado para dar a conocer en esta publicación.

Fue originario de esta ciudad, hijo de Nicolás Rivera Saravia y María de Lemus y San Miguel, y si atendemos a que en 1730 declaró tener cincuenta años de edad, ${ }^{1}$ su nacimiento debió ocurrir en 1680 . En 1722 se examinó como maestro de albañilería. ${ }^{2}$ En 1723 contrajo matrimonio con María Josefa Hidalgo Hurtado de Mendoza, dama beata, pues la mayor parte de su dote fueron cuadros de santos, a la par que liviana como en el testamento se verá.

En 1732 fue nombrado administrador de las casas y censos del Estado del Valle y del Hospital de la Limpia Concepción, ${ }^{3}$ cargo importante si consideramos las numerosas percepciones que disfrutaban los marqueses del Valle. Pero si el nombramiento lo encumbró en la escala social, debió por el contrario contribuir a separarlo del ejercicio de su profesión. En 1738, por algunas dificultades en el manejo de las cuentas - a las que no fue ajena su esposa - fue destituido del cargo, 4 y con esto perdió la vida de tanta pesadumbre que le ocasionó, pues a poco de su destitución enfermó de gravedad, otorgando testamento el 13 de enero de 1739. Murió no más de uno o dos días después, porque ya

1 Archivo General de la Nación. Ramo Vinculos y Mayorazgos, t. 221, exp. 2. Dato cortesía de Enrique Berlín.

2 AGN, Ramo Media Annata, t. 143. Dato cortesía de Enrique Berlin.

3 AGN, Hospital de Jesús, vol. 25, 1a parte, f. 7.

Ibid., leg. 397, exp. 17. 
el 17 siguiente aparece que fue practicado un embargo en los bienes de su testamentaría. $\overline{ }$

De sus actividades como arquitecto tengo conocimiento de las siguientes: en 1722 comenzó la construcción del Santo Desierto de Cuajimalpa que le encargaron los carmelitas descalzos, para sustituir al que a principios del siglo xvi había levantado fray Andrés de San Miguel. Rivera únicamente lo inició, haciendo la planta, los cimientos y acaso algunas varas de muro, dejando su ejecución para atender otras obras que tenía en México y que, según las actas de los Definitorios del Carmen, debian serle de mayor provecho. ${ }^{6}$ En estos mismos documentos se dice que antes había trabajado en la fábrica de los conventos de Toluca y San Joaquín. ${ }^{7}$

Del tiempo en que fue administrador de rentas del Estado y Hospital, existen numerosos recibos por la compra de madera y otros materiales pedidos por él para algunas obras, citándose las del convento de San Lorenzo, el obraje de Panzacola, la plaza del pueblo de San Agustín, una casa en la esquina de La Profesa y San Francisco, otras en San Agustín y el Empedradillo, las carrocerías de Tacuba y otras casas fronteras a la porteria de San Lorenzo. 8 Tratandose de casas pertenecientes al marquesado, su intervención sería la de un mero administrador, pero en otras, como la de la calle de San Agustín, que parece no eran del Estado, o el convento de San Lorenzo, podria pensarse que tuvo alguna participación como arquitecto; aunque también pudo ser sólo un intermediario. En 1738, en algún alegato, afirmaba haber procurado grandes economías a los marqueses, por el hecho de reunir a su cargo de administrador la calidad de arquitecto.

Gonzalo Obregón, que consultó el archivo del Colegio de las Vizcaínas, escribe que Rivera dirigió su construcción, por ser suya la firma que calza las memorias o listas de rayas y materiales. ${ }^{9}$ Existía para este colegio una planta dibujada por Pedro Bueno Basori, miembro de la cofradía de Nuestra Señora de Aranzazú que fue la que emprendió

5 Ibid., vol. 25, $2^{a}$ parte, f. 400 vta.

6 Eduardo Báez Macías. Obras de fray Andrès de San Miguel. México, Instituto de Investigaciones Estéticas de la UNAM, 1969, p. 28.

7 lbid.

8 AGN, Hospital de Jesús, vol. 25, 2a parte, exp. 7.

- Gonzalo Obregón. El Real Colegio de San Ignacio de México (Las Vizcainas). El Colegio de México, 1949, pp. 136-7. El mismo Rivera hace referencia a ciertos materiales sobrantes del Colegio de Vizcainas, en junio de 1737. AGN, Hospital de Jestis, vol. 25, 2a parte, exp. 7. 
la fundación. Pero además de que murió antes de que se pusiera siquiera la primera piedra, Basori no era arquitecto y si la suya es la planta que se encuentra en el Archivo de Indias y que se reproduce en el libro citado, difiere bastante de la planta actual del colegio, por lo cual me parece que es Miguel Rivera quien debe correr con el mérito de haberlo edificado en su mayor parte.

De otras actividades suyas tengo los siguientes datos que bondadosamente me ha proporcionado el investigador Enrique Berlin: En 1720 obtuvo el contrato para hacer la distribución de aguas, pilas y acueductos del río de Tlalnepantla, cuya corriente surtía hasta al Santuario de Guadalupe. ${ }^{10}$ En 1722 hizo un reconocimiento, en compañia de Antonio Alvarez, de unas casas situadas detras de la calle del Relox, cercanas a San Sebastián. ${ }^{11}$ En 1721 proyectó abrir nueva caja a los ríos de San Angel y Mixcoac, reparándoles los puentes. ${ }^{12}$

En 1723, asociado con Pedro de Arrieta, hizo un examen a los planos trazados por el arquitecto José Manuel de la Mata para redificar la Catedral de Oaxaca. ${ }^{13}$ En 1726, con el mismo Arrieta, inspeccionó unas casas localizadas frente al convento de Santa Clara. ${ }^{14}$ En 1727 hizo una alcantarilla en el puente del Hospital Real. ${ }^{15}$ En 1732 un reconocimiento a la planta presentada por Arrieta para ampliar la Inquisición; ${ }^{10}$ el mismo año un reconocimiento sobre unas casas en la calle de Cocheras. ${ }^{17}$ Entre 1732, y 1734 hizo varias inspecciones en compañía de Arrieta, unas veces, y de Custodio Durán y Eduardo Herrera, otras, sobre la obra de cantería y fábrica de la Real Casa de Moneda. ${ }^{18}$ En 1735, un reconocimiento a las cárceles secretas del Tribunal del Santo Oficio y otro a una casa en la calle de la Acequia. ${ }^{19}$ En 1738, en unión de José Eduardo Herrera, una inspección a la fábrica del Santo Oficio especialmente sobre "las cuatro danzas de arcos altas y bajas del patio principal", y asimismo un dictamen afirmando que la

10 AGN, Civil, vol. 258, exp. 4.

11 AGN, Civil, vol. 575 , f. 25.

12 AGN, Hospital de Jesuis, leg. 351, exp. 33.

13 AGN, Duplicados de Reales Cédulas, vol. 88, f. 49-56.

14 AGN, Vinculos y Mayorazgos, vol. 185, exp. 1.

15 AGN, Civil, vol. 57, exp. 1.

16 AGN, Inquisición, vol. 804, f. 25.

17 AGN, Vinculos y Mayorazgos, vol. 222, exp. 6 .

18 AGN, Casa de Moneda, vol. 177, f. 78 y 103 y vol. 230, f. 342 y 404.

10 AGN, Inquisición, vol. 625 , exp. 6 y Universidad, vol. 525, f. 86. 
Capilla del Rosario que se pensaba hacer en el convento de Santo Domingo pondría en peligro la fábrica de la Inquisición. ${ }^{20}$

En un alegato presentado en 1742 por Lorenzo Rodríguez contra Miguel Cusodio Durán, ${ }^{21}$ declara el primero que Miguel Rivera habia hecho la planta para la iglesia del Carmen.

Sobre estos planos trabajaron en la fábrica el citado Durán, quien no tardó en ser despedido, y José Eduardo Herrera que la dirigió hasta su consagración, en octubre de 1742 .

El testamento que publico es una segunda copia sacada del original, certificada por el escribano real y del Estado en octubre de 1740, 22 que exhibió Lonrenzo Rodriguez en la escuela de uno de los muchos pleitos en que se vio involucrada la sucesión de Rivera $y$, por ende, el arquitecto del Sagrario Metropolitano, que era su albacea testamentario. Dice así:

En el nombre de Dios Nuestro Señor Todopoderoso Amén: Notorio y manifiesto sea a todos los que la presente vieren como yo don Miguel de Rivera y Saravia, vecino y originario de esta ciudad de México, hijo legítimo de don Nicolás de Rivera y Saravia, nacional que fue de la jurisdicción de Guichiapa; y de doña María de Lemus y San Miguel, originaria del Real y Minas de Pachuca mis padres ya difuntos, estando enfermo en cama de la enfermedad que Dios Nuestro Señor ha sido servido darme, mas por su infinita misericordia en mi entero juicio, cumplida memoria y entendimiento natural, creyendo como firme y verdaderamente creo y de todo corazón confieso el altísimo e inefable misterio de la Santísima e inefable Trinidad Dios Padre, Dios Hijo y Dios Espíritu Santo, tres personas distintas y un solo Dios verdadero y en todos los demás misterios y sacramentos que tiene, cree y confiesa predicar y enseñar nuestra Santa Madre Iglesia Católica, Apostólica Romana, bajo de cuya fe y creencia he vivido y pretexto vivir y morir como católico y fiel cristiano que soy, eligiendo como elijo como mis intercesores y abogados a la Serenísima reina de los ángeles María Santísima, señora nuestra concebida en gracia desde su purísimo ser, al glorioso patriarca señor San José, su castísimo esposo, santo ángel de mi guarda, santos de mi nombre y demás de mi devoción, para que intercedan con Dios Nuestro Señor, perdone mis culpas y pecados y ponga mi alma en carrera de salvación y teniéndome de la muerte que es cosa - natural a toda viviente criatura y su hora incierta y dudosa, porque ésta no me coja desprevenido en las cosas tocantes al descargo de

20 AGN. Inquisición, vol. 869, f. 595-6.

21 ACN, Desagüe, vol. 11, exp. 62, f. 9-11.

22 AGN, Hospilal de Jestis, leg. 136, exp. 5. 
mi conciencia y bien de mi alma, otorgo que hago y ordeno mi testamento última y postrimera voluntad en la forma y manera siguiente:

1. La primera encomiendo mi alma a Dios Nuestro Señor que la creó y redimió con el infinito precio de su purísima sangre, pasión y muerte y el cuerpo a la tierra de que fue formado, el cual fallecido que sea se sepulte en la iglesia y capilla, parte - lugar que pareciere a mis albaceas a cuya disposición lo dejo con lo demás tocante a mi funeral y entierro.

2. Mando a las mandas forzosas y acostumbradas a peso cada una y otro peso para ayudar a la canonización del proto-mártir San Felipe de Jesús y otro peso de oro común para cada una de las beatificaciones de los venerables siervos de Dios Gregorio López, fray Sebastián de Aparicio, madre María de Jesús de Agreda e Ilustrísimo y Excelentísimo señor don Juan de Palafox y Mendo7a, con lo cual las desisto y aparto del derecho que a mis bienes pudieran repetir.

3. Declaro soy cofrade de distintas cofradias y hermandades cuyas patentes se hallarán entre mis papeles; es mi voluntad que fallecido que sea las remitan mis albaceas a los mayordomos y tesoreros para que cumplan con su obligación por haber yo cumplido con la mía y asimismo recauden de dichas cofradías, hermandades y congregaciones lo que a cada uno corresponde y esto lo convertirán en misas por mi alma o la pitanza ordinaria hasta donde alcanzare y si posible fuere se manden decir el día de mi fallecimiento por ser así mi voluntad.

4. Item. Declaro que soy casado y velado según orden de Nuestra Santa Madre Iglesia con María Josepha Hidalgo y al tiempo cuando contrajimos nuestro matrimonio no trajo a mi pocler la susodicha dote alguno, ni yo la he dotado ni doto en ninguna cantidad y al tiempo de dicha contracción me hallaba yo con el caudal de cinco mil pesos y durante dicho matrimonio no hemos tenido ni procreado hijos algunos. Declarolo así para que conste.

5. Item. Declaro que en mi casa y compañía tengo una niña nombrada María Josepha Micaela de Rivera que será de edad de quince años, la cual se bautizó por mi hija legítima, y para descargo de mi conciencia declaro que no lo es porque el suponerio fue falso como podré justificarlo dándome Dios vida y no pudiéndolo hacer lo ejecutarán mis albaceas en caso necesario como así se los dejo encargado, y así lo declaro para descargo de mi conciencia y que en todo tiempo conste.

6. Item. Declaro que la dicha mi mujer se ha separado de mi casa y compañía sin motivo alguno en diversas ocasiones llevándose 
consigo alhajas de mucha importancia, y siendo causa de haber yo experimentado muchos quebrantos, pérdidas y menoscabos y ningún aumento ni gananciales, porque cualesquiera que hava habido ha sido a mi solicitud y trabajo, y así lo declaro para que en ningún tiempo la dicha mi mujer pretenda derecho a mis bienes por razón de gananciales, y si acaso lo pretendiere se le repela por mis albaceas por las razones que llevo asentadas y así lo declaro para que conste.

7. Declaro que poseo por mía propia una casa entresolada que es en esta ciudad bajado el puente de San Francisco, contigua a la de trato de tocinería cuyos títulos paran en mi poder, y dicha casa se halla afecta a cierto gravamen, el cual consta por mis libros y asimismo a mis albaceas y asimismo declaro por mis bisnes todos los que se hallaren en la casa de mi morada, excepto algunas alhajas y prendas que las que son constan a dichos mis albaceas y dichos mis bienes se hallarán por menor sentadus en un libro de a folio que dejo entre mis papeles en el cual asimismo constan todas mi dependencias activas y pasivas, cuenta y razón de todas las que he tenido y así lo declaro para que conste.

Item. Es mi voluntad que de mis bienes se le den a Antonia y Gertrudis de Rivera, mis hermanas viudas, cien pesos a cada una que les aplico por vía de legado y donación intervivos, y asi lo declaro para que conste.

Item. Es mi voluntad que si alguno justificare ser mi hijo natural se le den de mis bienes cien pesos por vía de legado y para descargo de mi conciencia.

8. Item. Declaro fui fiador del capitán don Juan Esteban de Iturbide, caballero del orden de Santiago, difunto, y como tal lasté por el susodicho en el asiento de pulques la cantidad de dos mil pesos cuyo lasto se hallará entre mis papeles para que mis albaceas recauden dicha cantidad hallando alcanzar los bienes a dicho capitán y cobrada que sea dicha cantidad o parte de ella se entregue al reverendo padre fray Juan de Rivera mi hermano religioso de nuestro seráfico padre San Francisco, quien me está disponiendo para morir, para que lo que fuere, dicho reverendo padre lo distribuya en lo que le tengo comunicado para el descargo de mi conciencia sin que de ello se le pida ni tome cuenta por ningún juez ni prelado por ser así mi voluntad.

9. Y para cumplir y pagar este mi testamento y... el contenido nombro por mi albaceas testamentarios fideicomisarios en primer lugar a don Lorenzo Rodríguez, vecino de esta ciudad y maestro de Moneda en la Real Casa de esta corte; en segundo 
lugar al licenciado don Miguel de Yrusta, abogado de esta Real Audiencia y en tercero lugar a don Rodrigo Cienfuegos vecino asimismo de esta corte y por único tenedor de mis bienes al referido don Lorenzo Rodríguez, relevándolo como lo relevo de cualquiera fianza y gravamen por la entera satisfacción que tengo de sus cristianos y honrados procederes, y les doy el poder y facultad a los susodichos que por derecho se requiere para que entren en todos mis bienes, los inventarien, vendan y remaien en almoneda o fuera de ella como les pareciere y usen de dicho cargo todo el tiempo que hubieren menester aunque sea pasado el dispuesto por derecho; porque el más que necesitaren les prorrogo y alargo en debida forma.

10. Item. Es mi voluntad que a la dicha María Josepha Micaela de Rivera, niña doncella, se le den de mis bienes la cantidad de trescientos pesos, los que le aplico por vía de legado gracioso por el amor y cariño que le tengo, cuya cantidad se mantenga sin obligación de réditos en poder del referido don Lorenzo Rodríguez hasta tanto que la expresada María Josepha se ponga en estado y caso que fallezca antes de tomarlo quede dicha cantidad por cuerpo de mis bienes, y asi lo declaro para que conste, entendiéndose que la referida Maria Josepha ha de quedar a cargo y cuidado del expresado don Lorenzo Rodríguez hasta tanto que tome estado, por ser así mi voluntad.

11. Y en el remanente que quedare de todos mis bienes, derechos y acciones o futuras subcesiones que en cualquier manera me toquen $\mathrm{y}$ pertenezcan instituyo, elijo y nombro por mi único $\mathrm{y}$ universal heredero al referido don Lorenzo Rodríguez para que lo que así fuere lo haya, goce y herede con la bendición de Dios Nuestro Señor y la mía, en atención a no tener, corno no tengo, herederos forzosos ascendientes ni descendientes que conforme a derecho me puedan y deban heredar y con calidad y condición que el enunciado don Lorenzo Rodríguez, con el remanente de herencia funde una capellanía de misas por mi alma, las de mis padres y demás de mi intención, nombrándolo como descle luego lo nombro por primero patrono de ella y por primero capellán propietario de ella a un hijo del susodicho don Lorenzo Rodríguez, nombrado Mariano Antonio Rodríguez, que será de edad de catorce años, para que a su título se ordene hasta conseguir el sacro presbiterato gozando en el interín del superávit para sus alimentos y estudios, mandando decir las misas a la pitanza ordinaria de cuatro reales cuyo número haya de ser el de ciento en cada un año, las que se han de celebrar en la capilla de Nuestra Señora la Santísima Virgen María, advocación de Aranzazú sita en el convento de Señor San Francisco de esta corte y a falta del primero capellán nominado 
pueda dicho don Lorenzo nombrar otro del tronco, prefiriendo el mayor al menor verificándose así el patronato como el nombramiento del tal capellán siempre en los del tronco y a falta de esto sea patrono de la capellanía que así se fundare la mesa y diputados de Nuestra Señora de Aranzazú, sobre todo lo cual es mi voluntad no haya de tener intervención ninguna juez ni prelado, por dejarlo como lo dejo a la disposición del mencio. nado don Lorenzo Rodríguez. $Y$ es $\mathrm{mi}$ voluntad que las cien misas que se han de celebrar en cada un año se repartan en las festividades de Nuestro Señor Jesucristo, en las de Nuestra Señora la Santisima Virgen María, del Santísimo Patriarca Señor San José, arcángel señor San Miguel, santo ángel de la guarda y los demás días que pareciere al expresado don Lorenzo bajo de las condiciones referidas por ser así mi voluntad.

$Y$ por el presente revoco, anulo, doy por nulos de ningún valor ni efecto otros cualesquiera testamentos, poderes para testar, memorias y otras últimas disposiciones que antes de ésta haya hecho y otorgado por escrito, de palabra o en otra forma, para que no valgan ni hagan fe en juicio ni fuera de él, salvo el presente que quiero se guarde, cumpla y ejecute por mi última y postrera voluntad o en aquella vía y forma que más haya lugar en derecho, que es fecho en la ciudad de México en trece días del mes de enero de mil setecientos treinta y nueve años. $\mathrm{Y}$ yo el escribano que presente soy doy fe conozco al otorgante y a lo que notoriamente parece está en su entero juicio... Ante mí Joseph de Rivera Butrón. Escribano Real.

Rivera dispensaba un gran afecto a Lorenzo Rodríguez a quien heredó todos sus bienes con la excepción de los legados y mandas estipuladas en las cláusulas 2,7 y 10 . En la misma cláusula 7 se refiere concretamente a la casa que tenía bajando el puente de San Francisco (hoy esquina de Avenida Juárez y San Juan de Letrán) y que él mismo valuaba en doce mil pesos. Aparte de ésta, consta que dejó una berlinga, una silla volante, alhajas, vestidos, muebles, colgaduras, dos pares de pistolas, un trabuco, una espada, tres esclavas y, amén de otras cosas, una colección de cuadros y algunos libros, todo valuado en poco menos de veinte mil pesos.

A la muerte del testador, Lorenzo Rodríguez dejó la casa del Estado que ocupaba en el Empedradillo y se mudó a la del puente de San Francisco; supongo que para estar más cerca de la obra que hacía en la Capilla de San José de los Naturales, como se infiere de una diligencia que el escribano ejecutor del Estado practicó con María de Fuentes, esposa de Rodríguez: 
... se dio razón hallarse en la obra que se está haciendo en la capilla de los naturales del convento de nuestro padre San Francisco... y habiendo pasado a ella, presente en el cementerio dicho don Lorenzo Rodríguez... ${ }^{23}$

Tampoco hay que descartar, visto que Rodríguez trabajaba para el convento; alguna intervención suya en la fachada de Balvanera que poco después se labró.

Los cuadros que se hallaron en la casa de Rivera, según los inventarios, fueron los siguientes:

San Cristóbal, San Miguel, El Salvador, Santa Maria Magdalena, San Francisco Capuchino, dos con la Virgen de Guadalupe, cinco países dos retratos, Santa Lucrecia, Santa Gertrudis, San Juan Bautista, San Nicolás obispo, una Danza, Huida a Egipto, San Antonio, La Limpia Concepción, Virgen de los Dolores, Nuestra Señora de Loreto, EcceHomo, El Señor de la Columna, San Juan de Dios, La Encarnación, Santa Teresa, San Fernando, San Luis Rey, La Santisima Trinidad, Santa Catarina, San Felipe, Santa Rosa, Santa Verónica, dos lienzos con Los Infantes de Lara, una imagen de talla de La Limpia Concepción y otra de San Antonio, un Cristo de marfil y un lienzo con el mapa de México. ${ }^{24}$

Si grande parece la lista anterior, exigua resulta en cambio la de su biblioteca, sobre todo tratándose de un arquitecto, según la relación que hizo el escribano ejecutor:

Un armario de madera ordinaria y cedro como de una vara y tres cuartos en alto ... el cual fue abierto por mano de dicho don Lorenzo [Rodríguez] y dentro del se hallaron los papeles y libros y demás de que se hace mención. Primeramente un juego de nueve libros de a cuarterón forrados en pergamino intitulados Tosca: compendio matemático. Once libros de a folio forrados en pergamino, uno se intitula fray Laurencio y otro Vitruvio Pollion, de arquitectura. Otro que se compone sólo de varios mapas de arquitectura. Otro breve compendio de carpintería de lo blanco. Tres de La mistica ciudad de Dios. Luz de verdades católicas. Otro de la fundación de México. Otro que se intitula segunda parte de fray Laurencio. Otro de Sebastián Serlio, de antigüedades. Otro de a folio de la conquista de Nueva España. Otros nueve libros de cuarterón unos y otros más pequeños, uno intitulado Geometria de Euclides. Otro Elementos Matemáticos del padre

23 AGN, Hospital de Jesuis, vol. 25, 2a parte, f. 534.

24 lbid., f. 391. 
Ulloa. Otro Pasión de Cristo. Otro Historia Universal para explicar la continuación de la religión. Otro Toscano-dórico. Otro libro de a folio con cinco grabados ae arquitectura. Otro dicho de a folio con varios mapas con forro de papel de China... Un cuaderno en que parece tratarse de descripción de la obra de los vizcaínos, en diez fojas... Otro legajo que se compone de 22 fojas que parece ser ajuste que tuvo don Miguel de Rivera con don Juan García de la Huerta para la fábrica de una casa junto al puente de la Quebrada. ${ }^{25}$

En un inventario que en vida hizo con su propia mano, decía eI arquitecto tener, además de los arriba mencionados, los tres tomos de la madre Agreda y las doctrinas del padre Parra. Del cuaderno relativo a la obra en las Vizcaínas, solamente podemos lamentar la pérdida.

El fray Laurencio citado debe ser el Arte y uso de arquitectura de fray Lorenzo de San Nicolás, y el Compendio de carpinteria de lo Blanco el de Diego López Arenas, editado en 1633. De Vitruvio, para esa fecha ya se habían hecho varias ediciones, y de Serlio la muy conocida de 1552, con la traducción de Francisco Villalpando.

Además de los datos sobre Miguel Rivera, la documentación citada contiene noticias sobre arquitectos tan importantes como Arrieta, Yniesta Vexarano, Custodio Durán, el ya citado Lorenzo Rodríguez y otros menos conocidos, cuya obra aún está por estudiarse, como José Eduardo Herrera, José Antonio de Roa, Bernardo Alemán y Manuel Álvarez, estos últimos arquitectos del Marquesado del Valle registrados en el censo de población de 1753 .

A Rivera lo sepultaron el 16 de enero de 1739 en la capilla de Nuestra Señora de Aranzazú del convento de San Francisco, con cuya cofradía llevaba buenas relaciones, además de que a dicho convento pertenecía el hermano que cita en su testamento. Su entierro, dicen los documentos, costó doscientos pesos y llevó treinta acompañantes. ${ }^{26}$

25 lbid., exp. 8 , f. 400 vta. y vol. $25,1^{\text {a }}$ parte, f. $2-4$.

26 Ibid., vol, $25,1^{7}$ parte, f. 19 y 24. 